
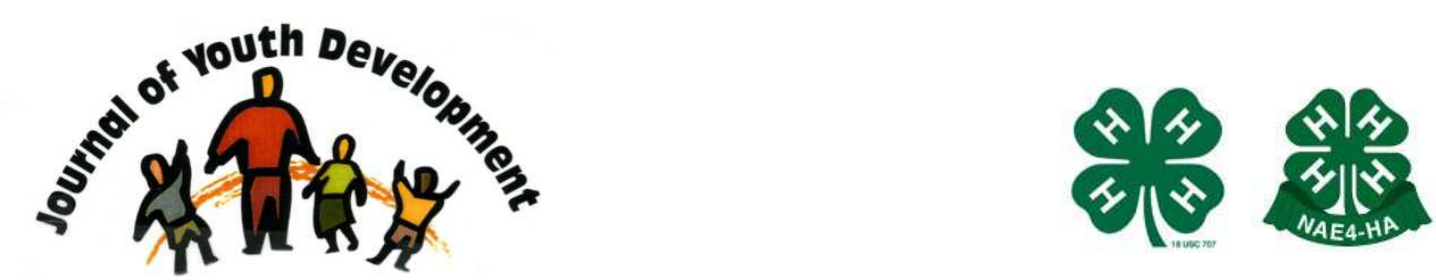

Bridging Research \& Practice

\title{
Examining the Potential Unintended Effects of a Healthful Living Curriculum Upon Children's Weight-Related Beliefs, Body Satisfaction, and Body Build Stereotypes
}

\author{
Jennifer Paff Ogle \\ Colorado State University \\ Fort Collins, CO \\ ogle@cahs.colostate.edu \\ Jan Carroll \\ Colorado State University \\ Fort Collins, CO \\ jan.carroll@colostate.edu \\ Brian Butki \\ Colorado State University \\ Fort Collins, CO \\ brian.butki@colostate.edu
Mary Lynn Damhorst
Iowa State University
Ames, IA
mldmhrst@iastate.edu \\ Susan Baker \\ Colorado State University \\ Fort Collins, CO \\ susan.baker@colostate.edu
}




\title{
JOURNAL OF YOUTH DEVELOPMENT \\ bridging research and practice

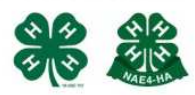

Volume 3, Number 3, Winter 2008

Article 080303FA006

\section{Examining the Potential Unintended Effects of a Healthful Living Curriculum Upon \\ Children's Weight-Related Beliefs, Body Satisfaction, and Body Build Stereotypes}

\author{
Jennifer Paff Ogle, Jan Carroll, Brian Butki and Susan Baker \\ Colorado State University \\ Mary Lynn Damhorst \\ Iowa State University
}

\begin{abstract}
This exploratory work was guided by the question of whether health education messages about food and exercise might inadvertently influence children's beliefs about weight controllability, body satisfaction, weight self-assessments, desire to alter weight, and body build stereotypes. Participants were 80 children (38 boys, 42 girls) aged 7 to 13 years enrolled in a week-long "FunLIFE" summer camp offered at a large university. FunLIFE was created in response to the childhood obesity crisis and focuses upon Learning to Improve Fitness and Eating (thus, the acronym "LIFE"). Pre- and posttest questionnaires were administered at four camp sessions. Findings indicated that participation in FunLIFE camp did not influence children's weight controllability beliefs, level of body satisfaction, their self-assessments of their weight, or their desire to alter or maintain their weight. Exposure to the FunLIFE curriculum did, however, positively impact children's stereotypes about both overweight and thin children. Findings and implications are discussed.
\end{abstract}

\section{Introduction}

\section{Childhood Obesity and Educational Programming}

In recent years, those who work with youth have become increasingly focused upon the development and delivery of curricula designed to promote healthful lifestyles among children (Dixey, Sahota, Atwal, \& Turner, 2001; White, Martin, \& Martin, 2007). These efforts have 
been made largely in response to increases in childhood overweight and obesity rates. Over the past three decades, the prevalence of obesity among American children has increased threefold (Ogden, Flegal, Carroll, \& Johnson, 2002). Current estimates suggest that $15 \%$ of American children between the ages of 6 and 19 years are overweight, placing them at risk for becoming overweight during adulthood and for developing a host of health problems as children, and subsequently, as adults (Fagot-Campagna, 2000; McGuire, Hannan, Neumark-Sztainer, Cossrow, \& Story, 2002; Neumark-Sztainer, Story, Resnick, \& Blum, 1996; Ogden, et al., 2002; Styne 2001).

Although there is increasing acknowledgement that genetics contribute to body size and shape (Aphramor, 2005; Campos, Saguy, Ernsberger, Oliver, \& Gaesser, 2006; Kater, 2006; Monaghan, 2005; Rich \& Evans, 2005), there is an expansive body of literature supporting the hypothesis that individual behavior - including diet and level of physical activity - also plays an important role in predicting risk for overweight and obesity (Koplan, Liverman, \& Kraak, 2005; Lindsay, Sussner, \& Gortmaker, 2006). Similarly, there is evidence to suggest that nutrition and exercise behaviors developed in childhood establish a basis for patterns later in life, and thus, have implications for adult health (McGuire et al., 2002; Neumark-Sztainer, et al., 1996). For these reasons, many of the educational programs created in response to the childhood overweight and obesity crisis have focused upon engendering healthful lifestyle patterns, including making healthful eating choices (e.g., limiting consumption of fats and sugars) and encouraging regular engagement in physical activity (e.g., Fitzgibbon, Stolley, Dyer, VanHorn, \& KauferChristoffel, 2002; Neumark-Sztainer, Story, Hannan, \& Rex, 2003).

\section{The FunLIFE Program}

One such program is the FunLIFE summer camp offered by the Department of Health and Exercise Science at a large land grant university in the western United States. Week-long FunLIFE camps target elementary school aged children and focus upon Learning to Improve Fitness and Eating (thus, the acronym "LIFE"). The FunLIFE camps are part of the university's Youth Sport Camps program and were created in 2004 in response to the childhood obesity epidemic and the concomitant reduction of time allocated to physical education programming in the local public schools. Camps run on a seven hour schedule, and programming is designed to teach age-appropriate healthy lifestyles, focusing specifically on nutrition (e.g., RDA recommendations, appropriate consumption of fruits and vegetables, importance of a low-fat diet, importance of limiting junk food consumption) and physical activity (e.g., aerobic activities, individual and team sports). Campers participate in physical and creative classroom activities examining nutrition, fitness, and healthy lifestyles. Some of these activities are based on national programs developed by Cooperative Extension, corporate entities, and recreation departments and others are created by the University camp staff specifically for FunLIFE.

Evaluations of the FunLIFE program suggest that the five-day camps are effective to some extent in improving knowledge about nutrition and physical activity. In a pre- and posttest comparison, campers improved their knowledge of fruits and vegetables but did not change snack selections as a result of participation in the camp. The researchers speculated that the lack of change in snack selection could be due to the fact that, at home, many children do not participate in making their own snack selections, but rather, eat what is provided by a caregiver. Physical activity knowledge scores also increased from pre-to posttest, but there were no group differences between FunLIFE campers and a control group in the amount of daily or weekly steps taken (Mattie, 2006; Mattie, \& Butki, 2007). Although these findings 
suggest that exposure to camp curriculum may not be sufficient for producing desired behavioral changes, they do indicate that there are some positive knowledge changes to be gained through participation in the FunLIFE program.

The present work builds upon that of Mattie and Butki (Mattie, 2006; Mattie, \& Butki, 2007) by continuing to explore the ways in which the FunLIFE curriculum may impact its young participants. However, this work is unique in that it examined the possibility of unintended consequences stemming from participation in FunLIFE camp. More specifically, this exploratory work was guided by the overarching question of whether health education messages about food and exercise - such as those presented as a part of the FunLIFE camp curriculum - might inadvertently influence children's beliefs about the extent to which weight is within one's personal control, their degree of body satisfaction, their assessment of their own weight, their desire to alter their own weight, and their stereotypes toward overweight and thin children.

\section{Justification and Hypotheses}

\section{The Cultural Conflation of Healthfulness and Thinness}

There is a growing body of scientific evidence suggesting that thinness, alone, should not be used as a barometer of physical well-being, but instead, should be considered in conjunction with factors such as fitness and genetic predisposition to disease (Aphramor, 2005; Campos, et al., 2006; Kater, 2006; Rich, \& Evans, 2005). Nonetheless, in today's cultural milieu, the distinction between behaviors enacted for purposes of health and those undertaken for purposes of appearance has become obscured to the extent that healthfulness has become conflated with thinness (Shilling, 2003). The thin and toned body is now perceived as the most desirable, and thus, the most healthful, moral, and valued (Bordo, 2003; Shilling, 2003).

Therefore, it is perhaps not surprising that for adults, the desire to modify appearance is a more significant factor in driving dieting behaviors than is concern with health (Hayes \& Ross, 1987).

Research indicates even young children embrace these widespread cultural messages about thinness and healthfulness. Elementary school aged children, including past FunLIFE campers, have been found to

(a) confuse healthy eating and dieting,

(b) associate health with dietary restraint, and

(c) perceive thinness as requisite to wellness (Blissett, Lyons, \& Norman, 1996; Hill, \& Silver, 1995; Ogle, Baker, Carroll, Butki, \& Damhorst, 2007).

Indeed, this is concerning because although certain self-care regimens (e.g., eating a lowfat diet, exercising regularly) undertaken to achieve a thin and toned body may promote health, adherence to radical diets may actually undermine rather than promote healthfulness (French, Perry, Leon, \& Fulkerson, 1995; Story, Neumark-Sztainer, Sherwood, Stang, \& Murray, 1998). Similarly, compulsive exercising can cause injury, fatigue, and excessive weight loss (De Coverly Veale, 1987; Wichmann, \& Martin, 1992).

\section{Healthfulness and the Ideology of Self-Control}

American children today also are socialized in a culture that emphasizes the role of personal volition in shaping the quality of one's healthfulness. This tradition has its roots in a Western culture ideology that reveres self-control (Shilling, 2003). When taken in conjunction with the 
cultural conflation of healthfulness with slenderness, this ideology contributes to the construction of overweight or obesity as a stigmatizing attribute and a sign of personal failure to appropriately control the body through diet and exercise (Rich, \& Evans, 2005; Quinn, \& Crocker, 1999). Further, in previous work, body attitudes have been shown to be negatively related to beliefs about body control (Ogle, Damhorst, \& Lee, 2005).

\section{Body Build Stereotypes}

There is evidence to suggest that adults and young children alike embrace negative cultural stereotypes about overweight individuals. Research indicates that the socialization to hold prejudices against overweight and obese persons begins early in life (Cramer, \& Steinwert, 1998). Elementary school aged children attribute negative personal characteristics to overweight people and express preferences not to associate with overweight peers (Cash, 1990; Felker, 1972; Tiggeman, \& Anesbury, 2000). Further, elementary school aged children have been found to view obesity as a matter of personal control - a perception that has been positively correlated with negative stereotypes about obese persons (Tiggerman, \& Anesbury, 2000). Research regarding stereotypes about thin children is somewhat less consistent, with some findings indicating that thin stereotypes include a combination of desirable social traits and negative physical capability traits (Brylinksy, \& Moore, 1994), and other work suggesting a more singularly positive (Stager, \& Burke, 1982) or negative (Lerner, \& Korn, 1972) thin child stereotype. Differences in method and the socio-cultural moment during which the data were collected have likely contributed, in part, to these discrepant findings.

\section{Hypotheses}

Dixey, et al. (2001) have posed the question of whether children might connect health education messages regarding the need to reduce fat in the diet (as a means by which to prevent heart disease) with being too fat or with a need to reduce fat on their own bodies.

The present study was designed to provide some preliminary insights regarding this overarching question. In light of the literature reviewed herein, we proposed the general hypothesis that participation in a curriculum emphasizing one's personal role in constructing a healthful body through maintenance of a "proper" diet and engagement in physical activity - could set a context that may change children's perceptions of the extent to which weight is controllable as well as their degree of satisfaction with their own bodies (Am I doing enough to control my own body?, Should I be doing more?), their perceptions about their own weight (including selfassessments and the desire to alter or maintain their weight), and their stereotypes about others' bodies. In previous work, beliefs about weight controllability have been found to be related to body attitudes and body build stereotypes (Ogle, et al., 2005; Tiggemann, \& Anesbury, 2000).

Specific hypotheses for this study were as follows:

H1: Participation in the FunLIFE camp will increase campers' perceptions of weight controllability.

H2: $\quad$ Participation in the FunLIFE camp will decrease campers' level of body satisfaction.

H3: Participation in the FunLIFE camp will change campers' self-assessments of their weight.

H4: Participation in the FunLIFE camp will change campers' stated desire to alter their weight. 
H5: Participation in the FunLIFE camp will increase campers' negative stereotypes about overweight children.

H6: Participation in the FunLIFE camp will decrease campers' negativity of stereotypes about thin children.

\section{Method}

\section{Sample and Data Collection}

As noted, the sample for this study included male and female children who had voluntarily enrolled in a week-long "Fun-LIFE" summer camp session at the local university. Tuition assistance for the program was available, and participants represented diverse ethnic and socioeconomic backgrounds. Because the camp is administered by a university, human subjects' permission to include the children in relevant research studies is routinely obtained from the campers and their parents.

Data were collected at four different camp sessions offered during the summer. For each camp session, the questionnaires were administered by camp counselors and the researchers on the first and last day of camp. Pretest data were collected prior to the presentation of curricular content related to nutrition, exercise, fitness, and health. For both pre- and posttest data collection, camp counselors read the questionnaire instructions aloud to the children. After children completed the posttest questionnaire, height and weight data were collected by the camp counselors and the researchers. Then, camp counselors presented curriculum related to body image and the notion that healthy or "fit" bodies can come in any size. This also served as a debriefing exercise for the study.

\section{Measures}

Perceptions of Weight Controllability. The extent to which children believe that weight is under one's personal control was measured using items adapted from Tiggemann's and Anesbury's (2000) Controllability Beliefs scale. Given the focus of the present study upon changes in attitudes toward body weight, only the items focusing upon weight and obesity were used; items related to beliefs about height controllability were omitted. Nine weight-related items from the scale were included in the questionnaire and addressed perceptions about causes of and solutions to overweight and obesity (e.g., "Do children have control over their weight?", "Can fat children become thin if they really try?"). Participants indicated the extent to which they believed the question to be true ("Yes"), false ("No), or were unsure of the answer ("Don't know"). To calculate an aggregate controllability score for each participant, a score of 1 was awarded for each answer that indicated controllability, .05 was awarded for each "don't know" response, and 0 was awarded for each response that indicated a lack of controllability. As such, scores on this scale could range from 0 to 9, with higher scores reflecting greater perceptions of controllability over one's weight. The Cronbach's alpha for this scale was 0.64 for the pretest and 0.72 for the posttest.

Body Esteem Scale. Children's affective evaluations of their bodies were measured using the Body Esteem Scale (Mendelson, \& White, 1982). This self-report scale, which is viewed as reliable for children seven years and older, contains 24 descriptive statements (e.g., "I like what I look like in pictures," "I'm proud of my body," and "My weight makes me unhappy") with "yes/no" responses. The measure is scored by counting the responses indicating high body esteem. Cronbach's alpha for this scale was 0.86 for the pretest and 0.89 for the posttest. 
Body Dissatisfaction. Body dissatisfaction also was assessed using a pictorial rating scale developed by Collins (1991) for use with children aged six and older. This measure includes seven child figures ranging in size from very thin (figure \#1) to obese (figure \#7). Separate scales are used to depict male and female figures, which are assigned corresponding values ranging from "1" (figure \#1) to "7" (figure \#7). For the present study, the facial features of the Collins' figure drawings, which are Caucasian in appearance, were removed to ensure that the scales were appropriate for use with diverse participants (Thompson, 1996; Wood, Becker, \& Thompson, 1996). To assess body dissatisfaction, participants were asked to respond to the following questions by circling the appropriate same-gender child figure of their choice: "Which picture looks the most like you look?" and "Which picture shows the way you want to look?" The discrepancy between these ratings was interpreted as an indicator of body dissatisfaction.

Weight Self-Assessment. Participants responded to two questions borrowed from Collins' (1991) work and designed to tap children's assessment of their current weight and desire to alter weight:

1. Weight self assessment: I think I am...fat, skinny, in-between

2. Desire to alter weight: I would like to...lose weight, stay the same, gain weight

Body Size Stereotyping. Body size stereotypes were measured using an approach similar to that used by Tiggemann and Anesbury (2000); Tiggemann and Wilson-Barrett (1998). Here, participants were presented with selected sets of figures from the Collins' (1991) figure rating scale1 and were asked to make judgments about the figures. The following pairs of figures were selected:

(a) a set including male figure \#4 (the mid-point or "average" sized figure) and male figure \#6 (the second-largest figure2),

(b) a set including male figure \#4 (the mid-point or "average" sized figure) and male figure \#1 (the thinnest figure),

(c) a set including female figure \#4 (the mid-point or "average" sized figure) and female figure \#6 (the second-largest figure), and

(d) a set including female figure \#4 (the mid-point or "average" sized figure) and female figure \#1 (the thinnest figure).

The second largest figure was selected for comparison with the average-sized figure because the largest figure (\#1) had been used in previous work (Tiggemann, \& Anesbury, 2000), and we were interested in examining whether the same stereotyping effects would hold for the slightly less overweight figure. Results of this analysis will be reported in a separate paper.

To avoid introducing any systematic bias related to the positioning of the figures, the averageweight figure was presented on the right side of the page for half of the participants and on the left side of the page for half of the participants. In all cases, the figure on the left side of the page was referred to as "Boy (Girl) A," and the figure on the right side was referred to as "Boy (Girl) B."

The same ten items were used to measure body size stereotypes for all four sets of figures, with participants asked to select between the two figures on each item. The first eight items 
focused upon personality judgments and asked participants to indicate which boy (girl) they thought was friendlier, happier, lazier, smarter, healthier, more attractive, more confident, and worked harder. The remaining two items focused upon issues of peer preference, and asked participants to indicate which boy (girl) they liked best and wanted to play with. In all cases, three response options were provided: "Boy (Girl) A," "Boy (Girl) B," and "Both the Same." All participants evaluated same gender figures first and opposite gender figures second.

A score of 1 was awarded for each response indicating negative stereotyping of the overweight or very thin (i.e., the non-average) figure. As such, total stereotype scores for each figure could range from 0 to 10 , with each scale containing two subscales: a personality subscale (scores ranging from 0 to 8 ) and a peer preferences subscale (scores ranging from 0 to 2). Cronbach's alphas for the pretest and posttest scales (respectively) were as follows: 0.77 and 0.85 for the overweight male figure scale, 0.77 and 0.86 for the overweight female figure scale, 0.79 and 0.81 for the very thin male figure scale, and 0.82 and 0.82 for the very thin female figure scale.

T-tests were conducted as a manipulation check to examine the possible influence of the positioning of the overweight/thin and average-sized figures on the page (i.e., right side versus left side) on participants' responses to the stereotyping items. Analyses revealed no significant differences in participants' responses based upon the figure positioning (all ps $>0.05$ ). That is, there was no order effect at work.

\section{Data Analysis}

Paired sample t-tests were used to compare pre- and posttest scores and to test Hypotheses 1, 2,5 , and 6 . Hypotheses 3 and 4 were tested using McNemar-Bowker Test, which is an extension of the Chi-square test that allows for the comparison of dependent, categorical data. In all cases, male and female analyses were run separately to allow potential gender differences to be revealed. The significance level for the tests was set at 0.05 .

\section{Results}

\section{Sample Characteristics}

Participants were 80 children ( 38 boys, 42 girls) aged 7 to 13 years $(M=9.30$ years, SD = 1.76) enrolled in the FunLIFE summer camp program. The FunLIFE program is offered within a vibrant and diverse university community. A formal attempt was made to collect participant ethnicity data via a parent questionnaire. This measure was taken in response to concerns about children's capacity to accurately report ethnicity. Very few parent questionnaires, however, were returned. As such, a specific breakdown of participant ethnicity cannot be reported.

Body Mass Index (BMI), an estimate of body fatness that is adjusted for height, was calculated by using the following formula (Center for Disease Control [CDC], 2007): BMI = (weight in pounds $\times$ 703)/(height in inches). The range for a normal BMI changes with a child's age and gender and must be interpreted using a BMI-for-age chart (CDC, 2007). If BMI-for-age is greater than or equal to the 95th percentile, the child is considered overweight. A score between the 85th and $94^{\text {th }}$ percentiles places a child at risk for of overweight. Mean BMI scores for the present sample are presented by age and gender group in Table 1. Mean BMI scores for the younger children participating in this study (i.e., those in the 7 to 8 year old group and 
in the 9 to 10 year old group) approached or exceeded the 85th percentile for both gender groups, which represented some risk of overweight. There was, however, a great deal of variation in the BMI scores for the females in the 9 to 10 year old group $(S D=7.15)$. The mean BMIs for the 11 to 13 year old children in the sample were below the 85th percentile cutoffs and suggested that, on average, male and female participants in this age group maintained healthy weights.

Table 1

Body Mass Index Scores by Age and Gender: Means and Standard Deviations

\begin{tabular}{|l|l|l|l|l|}
\hline & \multicolumn{2}{|c|}{ Males } & \multicolumn{2}{c|}{ Females } \\
\hline Age in years & n & M (SD) & $n$ & M (SD) \\
\hline 7 to 8 & 19 & $17.59(3.42)$ & 16 & $17.83(3.14)$ \\
\hline 9 to 10 & 11 & $19.48(3.73)$ & 13 & $19.33(7.15)$ \\
\hline 11 to 13 & 8 & $19.90(3.16)$ & 13 & $19.56(2.67)$ \\
\hline
\end{tabular}

Note: At 7, 9, and 12 years of age, the BMI-for-age scores at the $85 \%$ percentile (the threshold for being considered "at risk" for overweight) are approximately 17.4, 18.6, and 21 (males) and 18, 19, and 21.6 (females) (CDC, 2007).

\section{Hypothesis Testing}

As noted, the aim of this work was to explore the potential unintended influence of participation in a given nutrition and fitness education program upon children's perceptions of weight controllability, degree of body satisfaction, self-assessments of weight, stated desire to alter weight, and body build stereotypes. Results of paired sample t-tests are presented in Table 2. As the contents of Table 2 indicate, findings did not confirm Hypothesis 1 . There were no significant differences between male campers' or female campers' pre- and posttest scores on the controllability beliefs measure $(t=-1.12, p>0.05$ and $t=-1.16, p>0.05$, respectively). That is, participation in the FunLIFE camp had no statistically measurable impact on male or female campers' perceptions of weight controllability. As the data in Table 2 indicate, even prior to the presentation of the camp curriculum, both male and female campers held moderately strong beliefs in human capacity to change weight $(M=6.68$ and $M=6.05$, respectively). 
Table 2

Paired Sample T-tests Comparing Pre- and Posttest Scores on Perception of Weight Controllability, Body Esteem, Collins' Pictorial Rating Scale of Body Satisfaction, and Body Build Stereotypes

\begin{tabular}{|c|c|c|c|}
\hline Measure & $\begin{array}{c}\text { Pretest Mean } \\
\text { (SD) }\end{array}$ & $\begin{array}{c}\text { Posttest Mean } \\
\text { (SD) }\end{array}$ & $\mathbf{t}$ \\
\hline \multicolumn{4}{|l|}{ Males $(n=38)$} \\
\hline Perceptions of Weight Controllability & $6.68(1.48)$ & $6.89(1.32)$ & -1.12 \\
\hline Body Esteem Scale & $16.66(4.49)$ & $17.03(5.75)$ & -0.52 \\
\hline Collins' Pictorial Scale & $-0.35(0.86)$ & $-0.30(0.85)$ & -0.44 \\
\hline Stereotypes about overweight males - personality subscale & $5.34(1.96)$ & $4.97(2.33)$ & 0.91 \\
\hline Stereotypes about overweight males - peer preferences subscale & $1.42(0.72)$ & $1.36(0.85)$ & 0.36 \\
\hline Stereotypes about overweight females - personality subscale & $5.39(2.11)$ & $4.68(2.68)$ & $2.06 *$ \\
\hline Stereotypes about overweight females - peer preferences subscale & $1.58(0.76)$ & $1.24(0.97)$ & $2.83 * *$ \\
\hline Stereotypes about very thin males - personality subscale & $3.50(2.19)$ & $3.47(0.90)$ & 0.00 \\
\hline Stereotypes about very thin males - peer preferences subscale & $1.18(0.87)$ & $1.18(0.90)$ & 0.00 \\
\hline Stereotypes about very thin females - personality subscale & $3.68(2.56)$ & $3.11(2.56)$ & 1.42 \\
\hline Stereotypes about very thin females - peer preferences subscale & $1.34(0.88)$ & $0.89(0.98)$ & $3.09 * *$ \\
\hline \multicolumn{4}{|l|}{ Females $(n=42)$} \\
\hline Perceptions of Weight Controllability & $6.05(2.07)$ & $6.27(2.12)$ & -1.16 \\
\hline Body Esteem Scale & $19.55(4.96)$ & $19.24(5.06)$ & 0.81 \\
\hline Collins' Pictorial Scale & $-0.44(0.86)$ & $-0.37(0.85)$ & -0.55 \\
\hline Stereotypes about overweight males - personality subscale & $4.81(2.21)$ & $4.69(2.42)$ & 0.47 \\
\hline Stereotypes about overweight males - peer preferences subscale & $1.31(0.75)$ & $1.14(0.84)$ & 1.14 \\
\hline Stereotypes about overweight females - personality subscale & $4.88(2.03)$ & $4.57(2.35)$ & 0.96 \\
\hline Stereotypes about overweight females - peer preferences subscale & $0.95(0.82)$ & $1.00(0.86)$ & -0.42 \\
\hline Stereotypes about very thin males - personality subscale & $3.90(2.22)$ & $3.45(2.49)$ & 1.67 \\
\hline Stereotypes about very thin males - peer preferences subscale & $1.40(0.77)$ & $1.19(0.89)$ & $2.46 * *$ \\
\hline Stereotypes about very thin females - personality subscale & $3.57(2.09)$ & $3.43(2.19)$ & 0.59 \\
\hline Stereotypes about very thin females - peer preferences subscale & $1.26(0.86)$ & $1.00(0.91)$ & $1.98^{*}$ \\
\hline
\end{tabular}

${ }^{*} \mathrm{p}<0.05,{ }^{* *} \mathrm{p}<0.01$ 
Hypothesis 2 also was rejected. There were no significant differences in males' or females' preand posttest scores on the body esteem scale $(t=-0.52, p>0.05$ and $t=0.81, p>0.05$, respectively) or the Collins' pictorial rating scale $(t=-0.44, p>0.05$ and $t=-0.55, p>0.05$, respectively). Thus, according to these data, participation in this summer camp program did not impact children's level of body affect. On the whole, mean scores on the Body Esteem Scale, particularly for female participants, reflected rather positive body attitudes among the present sample (see Table 2). However, an interpretation of the pre- and posttest mean scores on the Collins' measure suggests that both male and female campers did desire to be somewhat slimmer than they perceived themselves to be (as indicated by the negative mean values) (see Table 2). This finding is consistent with previous work employing figure rating scales to examine body size dissatisfaction among children (Tiggemann, \& Pennington, 1990) and is perhaps not surprising, given the somewhat elevated BMI scores for the younger children in the sample.

To test Hypotheses 3 and 4, the McNemar Bowker test was used to compare participants' preand posttest scores on Collins' weight self-assessment and desire to alter weight items. Both hypotheses were rejected; participation in the FunLIFE camp did not significantly influence male or female participants' scores on either item (all ps > 0.05). The Chi-square values for the comparison of the males' and females' pre- and posttest weight assessment and desire to alter weight scores were $3.80,4.00,3.67$, and 2.00 , respectively. The distribution of pre- and posttest responses is presented in Table 3. A follow-up Chi-square test was conducted on the males' and females' pre- and posttest responses, with results suggesting that the distributions were not uniform (all ps $<0.01$, see Table 3 ). For both the pre- and the posttest assessments, male and female participants most frequently selected "in-between" as the response to the weight self-assessment item. For the desire to change weight item, "stay the same" was the most commonly selected response among male and female campers on both the pre- and the posttest measure.

Table 3

Frequency Distribution of Responses on Weight Self-Assessment and Desire to change Weight pre- and Posttest Scores for Male and Female Participants

\begin{tabular}{|c|c|c|c|c|c|c|c|c|}
\hline \multirow[b]{2}{*}{$\begin{array}{l}\text { Weight Self } \\
\text { Assessment }\end{array}$} & \multicolumn{4}{|c|}{$\begin{array}{l}\text { Males } \\
n=38\end{array}$} & \multicolumn{4}{|c|}{$\begin{array}{c}\text { Females } \\
n=42\end{array}$} \\
\hline & $x^{2}$ & Skinny & In-Between & Fat & $\mathbf{x}^{2}$ & Skinny & In-Between & Fat \\
\hline Pretest & $7.81 *$ & 10 & 27 & 0 & $27.85^{* *}$ & 9 & 28 & 2 \\
\hline Posttest & $34.43 * *$ & 6 & 29 & 2 & $46.29 * *$ & 6 & 34 & 1 \\
\hline $\begin{array}{l}\text { Desire to } \\
\text { Change } \\
\text { Weight }\end{array}$ & $x^{2}$ & Lose & $\begin{array}{c}\text { Stay the } \\
\text { Same }\end{array}$ & Gain & $\mathbf{x}^{2}$ & Lose & $\begin{array}{c}\text { Stay the } \\
\text { Same }\end{array}$ & Gain \\
\hline Pretest & $19.68 * *$ & 13 & 23 & 1 & $19.08^{* *}$ & 11 & 25 & 3 \\
\hline Posttest & $22.11^{* *}$ & 10 & 25 & 2 & $23.17^{* *}$ & 12 & 27 & 2 \\
\hline
\end{tabular}


Hypotheses 5 and 6 were tested by comparing pre- and posttest scores on the personality and peer preferences subscales for both the overweight and very thin male and female child stereotype scales. Results of these paired sample t-tests indicated some change, but not always in the anticipated direction. As the data in Table 2 indicate, Hypothesis 5 was not supported; participation in the FunLIFE camp was not shown to increase children's negative stereotypes about overweight children. Findings did indicate, however, that male campers' scores reflected less bias toward the overweight female figure on the personality subscale items $(\mathrm{t}=2.06, \mathrm{p}<0.05, \mathrm{M}=5.39$ vs. $\mathrm{M}=4.68$ ) as well as the peer preference subscale items $(\mathrm{t}=2.83, \mathrm{p}<0.01, \mathrm{M}=1.58$ vs. $\mathrm{M}=1.24)$. Hypothesis 6 received some support. Among male campers, findings revealed a decrease in negative stereotypes toward the very thin female figure on the peer preference subscale items $(t=3.09, p<0.01, M=1.34$ vs. $M=0.89)$. Results indicated a significant decrease in female campers' pre- and posttest scores on the peer preference subscale items for stereotypes of very thin male figures $(t=2.46, p<0.01, M=$ 1.40 vs. $M=1.19)$ as well as very thin female figures $(t=1.98, p<0.05, M=1.26$ vs. $M=$ 1.00). Thus, as expected, participation in the FunLIFE camp decreased campers' negativity of stereotypes about thin children.

\section{Concluding Discussion}

As noted, Dixey, et al. (2001) raised the intriguing query of whether well-intentioned health curricula designed to encourage lowfat diets and thereby reduce risk for heart disease might inadvertently incur negative body image-related consequences for young participants. Findings from the present study suggest that, at least with respect to the FunLIFE curriculum, the answer to this question is "no." Findings indicated that participation in the FunLIFE summer camp did not influence children's level of body satisfaction, their self-assessments of their weight, or their stated desire to alter or to maintain their weight. Similarly, results indicated that participation in FunLIFE did not change campers' perceptions about the extent to which weight is under one's personal control. From a programming perspective, then, these findings are encouraging; the FunLIFE curriculum achieved its intended aims of improving nutrition and fitness knowledge (Mattie, 2006; Mattie, \& Butki, 2007) and did not incur unintended outcomes that could have potentially deleterious impacts (e.g., decreased body satisfaction, increased negative stereotypes toward persons whose bodies deviate from 'average" sizes).

Interestingly, results did indicate that exposure to the camp curriculum positively impacted children's stereotypes about both overweight and thin children. One might speculate that some aspect of the camp curriculum increased positivity toward people of diverse sizes. The decreased negativity toward overweight persons is certainly a hopeful finding, especially when interpreted in light of previous work suggesting that children who adopt stereotypes about overweight persons may tease overweight peers, which in turn, may produce body dissatisfaction and low self-esteem among the targets of this teasing (Stormer, \& Thompson, 1996; van den Berg, Wertheim, Thompson, \& Paxton, 2002).

Future work might further explore what aspect of the camp curriculum contributed to this effect. Further, although the increased positivity toward very thin children may be considered encouraging from a social issues perspective, it also could be interpreted as somewhat disconcerting. This is particularly true given the excessively thin size of the stimulus figure used in the present study and the notion that although increases in childhood overweight and obesity 
are, indeed, alarming, they are paralleled by concerns about eating disorders and a growing preoccupation with dieting and the achievement of thinness among children (Field, et al., 2001; McVey, Tweed, \& Blackmore, 2004).

Given the relatively small sample and the use of a repeated measures approach, findings from this work should be interpreted somewhat cautiously. Additionally, it is important to recognize that by virtue of their enrollment in a healthy lifestyle camp, it is possible that participants in the present study were identified by their parents as in need of the information presented in this camp (e.g., perhaps they were perceived as having poor eating habits, as being sedentary, or as being at risk for overweight). Or, perhaps the participants were being raised by parents who were inclined to value healthfulness and who therefore encouraged their children's involvement in the camp. As such, the experiences of children in this sample may be unique in some way, and it will be important for future researchers to explore the beliefs of children using larger samples free of this potential bias. Further, in the future, it will be helpful to assess how content directly addressing body image concepts might shape some of the outcome variables explored in the present study, perhaps by expanding the debriefing content into a full educational unit and repeating the present analysis after it has been presented as part of the camp curriculum.

\section{References}

Aphramor, L. (2005). Is a weight-centered health framework salutogenic? Some thoughts on unhinging certain dietary ideologies. Social Theory \& Health, 3, 315-340.

Blissett, J., Lyons, T., \& Norman, P. (1996). Dieting behaviour and views of young children in Wales. Health Education Journal, 55(1), 101-107.

Bordo, S. (2003). Unbearable weight: feminism, western culture, and the body $\left(10^{\text {th }}\right.$ anniversary ed.). Berkeley: University of California Press.

Bryllinsky, J.A., \& Moore, J.C. (1994). The identification of body build stereotypes in young children. Journal of Research in Personality, 28(2), 170-181.

Campos, P., Saguy, A., Ernsberger, P., Oliver, E., \& Gaesser, G. (2006). The epidemiology of overweight and obesity: Public health crisis or moral panic? International Journal of Epidemiology, 35(1), 55-60.

Cash, T.F. (1990). The psychology of physical appearance: Aesthetics, attributes, and images. In T.F. Cash \& T. Pruzinsky (Eds.), Body images: Development, deviance, and change (pp. 5179). New York: Guilford Press.

Center for Disease Control. (2007). About BMI for children and teens. Retrieved December 14, 2007 from http://www.cdc.gov/nccdphp/dnpa/bmi/childrens BMI/about childrens BMI.htm

Collins, M.E. (1991). Body figure perceptions and preferences among preadolescent children. International Journal of Eating Disorders, 10(2), 199-208.

Cramer, P., \& Steinwert, T. (1998). Thin is good, fat is bad: How early does it begin? Journal of Applied Developmental Psychology, 19(3), 429-451. 
De Coverly Veale, D.M.W. (1987). Exercise dependence. British Journal of Addiction, 82, 735740.

Dixey, R., Sahota, P., Atwal, S., \& Turner, A. (2001). "Ha, ha, you're fat, we're strong": A qualitative study of boys' and girls' perceptions of fatness, thinness, social pressures, and health using focus groups. Health Education, 101(5), 206-216.

Fagot-Campagna, A. (2000). Emergence of type 2 diabetes mellitus in children: Epidemiologic evidence. Journal of Pediatric Endrocrinology and Metabolism, 13(6),1395-1405.

Felker, D. (1972). Social stereotyping of male and female body types with differing facial expressions by elementary age boys and girls. Journal of Psychology, 82(first half), 151-154.

Field, A., Carmago, C., Taylor, B., Berkey, C., Roberts, S.B., \& Colditz, G.A. (2001, January). Peer, parent and media influences on development of weight and shape concerns and frequent dieting among preadolescent and adolescent girls and boys. Pediatrics, 1071), 54-60.

Fitzgibbon, M.L., Stolley, M.R., Dyer, A.R., VanHorn, L., \& KauferChristoffel, K. (2002). A community-based obesity prevention program for minority children: Rationale and study design for Hip-Hop to Health Jr. Preventive Medicine, 34(2), 289-297.

French, S.A., Perry, C.L., Leon, G R., Fulkerson, J.A. (1995). Changes in psychosocial variables and health behaviors by dieting status over a three-year period in a cohort of adolescent females. Journal of Adolescent Health, 16, 438-447.

Hayes, D., \& Ross, C.E. (1987). Concern with appearance, health beliefs, and eating habits. Journal of Health and Social Behavior, 28, 120-130.

Hill, A.J., \& Silver, E.K. (1995). Fat, friendliness, and unhealthy: 9-year old children's perception of body shape stereotypes. International Journal of Obesity and Related Metabolic Disorders, 19, 423-430.

Kater, K.J. (2006). Promotion of healthy weight: Helping without harming. In Connect Teacher's Innovations in K-8 Science, Math and Technology, Synergy Learning, Vol.19, \#5.

Koplan, J.P., Liverman, C.T., \& Kraak, V.I. (2005). Preventing childhood obesity: Health in the balance: Executive summary. Journal of the American Dietetic Association, 105(1), 131-138.

Lerner, R.M., \& Korn, S.J. (1972). The development of body-build stereotypes in males. Child Development, 43(3), 980-920.

Lindsay, A.C., Sussner, K.M., \& Gortmaker, S. (2006). The role of parents in preventing childhood obesity. Future Child, 16, 169-186.

Mattie, E. (2006). The effectiveness of health-based summer camps in improving knowledge and behavior and influencing behavior change in children: A pilot study. Unpublished Master's Thesis, Colorado State University, Fort Collins, Colorado. 
Mattie, E. \& Butki, B. (2007, October). The effectiveness of health-based summer camps in improving knowledge and behavior and influencing behavior change in children: A pilot study. Poster presented at the annual conference of the Association for Applied Sport Psychology, Louisville, KY.

McGuire, M.T., Hannan, P.J., Neumark-Sztainer, D., Cossrow, N.H.F., \& Story, M. (2002). Parental correlates of physical activity in a racially/ethnically diverse adolescent sample. Journal of Adolescent Health, 30, 253-261.

McVey, G., Tweed, S., \& Blackmore, E. (2004). Dieting among preadolescent and young adolescent females. Canadian Medical Association Journal, 170(10), 1559-1561.

Mendelson, B.K., \& White, D.R. (1982). Relation between body-esteem and self-esteem of obese and normal children. Perceptual and Motor Skills, 54, 899-905.

Monaghan, L.F. (2005). Discussion piece: A critical take on the obesity debate. Social Theory and Health, 3, 302-314.

Neumark-Sztainer, D., Story, M., Hannan, P.J., \& Rex, J. (2003). New Moves: A school-based obesity prevention program for adolescent girls. Preventive Medicine, 371), 41-51.

Neumark-Sztainer, D., Story, M., Resnick, M.D., \& Blum, R.W. (1996). Correlates of inadequate fruit and vegetable consumption among adolescents. Preventive Medicine, 25, 497-505.

Ogden, C.L., Flegal, K.M., Carroll, M.D., \& Johnson, C.L. (2002). Prevalence and trends in obesity among U.S. children and adolescents, 1999-2000. Journal of American Medical Association, 288(14), 1728-1732.

Ogle, J.P., Baker, S.S., Carroll, J.B., Butki, B.D., \& Damhorst, M.L. (2007). A preliminary study of the meanings children attach to healthy and unhealthy lifestyles. Journal of Extension, 45(5), Article 5FEA4. Retrieved October 29, 2007, from:

http://www.joe.org/joe/2007october/a4.shtml

Ogle, J.P., Damhorst, M.L., \& Lee, H.H. (2005). Perceptions of body malleability: Linkages with body-related feelings and behaviors among undergraduate women and men. Family and Consumer Sciences Research Journal, 34(1), 35-56.

Quinn, D.M., \& Crocker, J. (1999). When ideology hurts: Effects of belief in the Protestant ethic and feeling overweight on the psychological well-being of women. Journal of Personality and Social Psychology, 77(2), 402-414.

Rich, E., \& Evans, J. (2005). Fat ethics' - The obesity discourse and body politics. Social Theory \& Health, 3, 341-358.

Shilling, C. (2003). The body and social theory ( $2^{\text {nd }}$ ed.). Thousand Oaks, CA: Sage.

Stager, S.F., \& Burke, P.J. (1982). A reexamination of body build stereotypes. Journal of Research in Personality, 16, 435-446. 
Story, M., Neumark-Sztainer, D., Sherwood, N., Stang, J., \& Murray, D. (1998). Dieting status and its relationship to eating and physical activity behaviors in a representative sample of US adolescents. Journal of the American Dietetic Association, 98(10), 1127-1135.

Stormer, S.M., \& Thompson, J.K. (1996). Explanations of body image disturbance: A test of maturational status, negative verbal commentary, social comparison, and socio-cultural hypotheses. International Journal of Eating Disorders, 19(2), 193-202.

Styne, D.M. (2001). Childhood and adolescent obesity: Prevalence and significance. Pediatric Clinics of North America, 48(4), 823-854.

Thompson, J.K. (1996). Assessing body image disturbance: Measures, methodology, and implementation. In J.K. Thompson (Ed.), Body image, eating disorders, and obesity: An integrative guide for assessment and treatment (pp. $49-81$ ). Washington, DC: American Psychological Association.

Tiggemann, M., \& Anesbury, T. (2000). Negative stereotyping of obesity in children: The role of controllability beliefs. Journal of Applied Social Psychology, 30(9), 1977-1993.

Tiggemann, M., \& Pennington, B. (1990). The development of gender differences in body-size dissatisfaction. Australian Psychologist, 25(3), 306-313.

Tiggemann, M., \& Wilson-Barrett, E. (1998). Children's figure ratings: Relationship to selfesteem and negative stereotyping. International Journal of Eating Disorders, 23(1), 83-88.

van den Berg, P., Wertheim, E.H., Thompson, J.K., \& Paxton, S.J. (2002). Development of body image, eating disturbance, and general psychological functioning in adolescent females: A replication using covariance structure modeling in and Australian sample. International Journal of Eating Disorders, 32(3), 46-51.

Wichmann, S., \& Martin, D.R. (1992). Exercise excess: Treating patients addicted to fitness. The Physician and Sports Medicine, 20, 193-200.

White, M., Martin, S.L., \& Martin, M. (2007). NikeGO: A corporate-sponsored program to increase physical activity and foster youth development. Journal of Youth Development: Bridging Research and Practice, 2(1), Article 0701PA002. Retrieved January 3, 2008, from: http://www.nae4ha.org/directory/jyd/jyd article.aspx?id=84b8595f-675f-44c0-ae817cbc3edd7031

Wood, K.C., Becker, J.A., \& Thompson, J.K. (1996). Body image dissatisfaction in preadolescent children. Journal of Developmental Psychology, 17, 85-100.

(C) Copyright of Journal of Youth Development Bridging Research and Practice. Content may not be copied or emailed to multiple sites or posted to a listserv without copyright holder's express written permission. Contact Editor at: patricia.dawson@oregonstate.edu for details. However, users may print, download or email articles for individual use.

ISSN 2325-4009 (Print); ISSN 2325-4017 (Online) 